\title{
Erratum to: Newly discovered diversity in the tropical fern genus Metaxya based on morphology and molecular phylogenetic analyses
}

Glenda G. Cárdenas ${ }^{1}$, Hanna Tuomisto ${ }^{1}$ \& Samuli Lehtonen ${ }^{1}$

Erratum to: KEW BULLETIN (2016) 71: 5 DOI 10.1007/S12225-016-9618-9

The original version of this article unfortunately contains an error in Fig. 5 whereby the caption mismatches the images. The correct version of the caption is presented below:

Fig. 5. Metaxya species in the field. A M. lanosa; B M. elongata; $\mathbf{C}$ M. rostrata $; \mathbf{D}$ M. parkeri $; \mathbf{E}$ M. contamanensis $\mathbf{F}$ M. scalaris. PHOTOS: A - E HANNA TUOMISTO, $\mathbf{F}$ SAMULI LEHTONEN. 